\title{
Chen, Lai 陳來, The Ontology of Ren 仁學本體論
}

Beijing 北京: Sanlian Shudian 三聯書店, 2014, 503 pages

\author{
Ning $W_{U^{1}}$
}

Published online: 5 July 2015

(C) The Author(s) 2015. This article is published with open access at Springerlink.com

Soon after this book was published last summer, some scholars acknowledged that it clearly shows an ambition to rebuild a magnificent mansion of Confucian philosophy in a traditional style. Humanity (ren 仁) is the most essential notion which has predominated the history of Confucianism from the pre-Qin 秦 period to today. The book is broad in conception and meticulous in detail, not only to demonstrate and elucidate the idea of humanity in the history of philosophy, but to develop a new form of ontology, even metaphysics.

In light of the book's content, it is not easy to find an appropriate English translation for its title. CHEN Lai 陳來 suggests that we have to be very careful when using such terms as "ontology" or "metaphysics" in the context of Chinese philosophy. The root of the term "ontology" can be traced back to $o \nu$ in ancient Greek philosophy, which means "being." There was no such an equivalent in ancient Chinese philosophy and, therefore, there was no ontology in China's tradition. Nevertheless, Chinese philosophers have been deeply concerned with and discussed the most fundamental, real, and ultimate existence from the perspective of benti 本體, which etymologically means "root" (ben 本) and "body" ( $t i$ 體), respectively. Therefore, there are ontology and metaphysics in ancient China, which could be defined in the way German philosopher Christian Wolff defined it. This argument for the necessity of ontology and metaphysics under the context of Chinese philosophy makes sense and will evoke further disputation.

The main concern of this book is to demonstrate the continuing relevance of traditional Confucian philosophy in modern China and the rest of the world. Unexpectedly, Chen begins the volume with the Kantian question "what is a human?" The fact that Chen values this question more than other Kantian questions implies what the book really focuses on.

Ning Wu

wuning5@mail.sysu.edu.cn

1 Liberal Arts College, Sun Yat-sen University, 135 Xingangxi Road, Haizhu, Guangzhou, Guangdong Province 510275, China 
The volume consists of a preface and twelve chapters. The closely-knit chapters each focuses on a different theme. In the first chapter, based on CHENG Hao's 程影 idea that the man of humanity forms one body with all things without any differentiation (renzhe yi tiandi wanwu wei yiti 仁者以天地萬物為一體), Chen develops the metaphysical and ontological aspects of humanity by investigating the ultimate integration of self with all things, thus obtaining dual significances: spiritual realm (jingshen jingjie 精神境界) and entity. In this part, Chen actually refutes Mou Zongsan's 牟宗三 famous criticism to ZHU $\mathrm{Xi}$ 朱喜 by expounding Zhu's idea of flowing vital qi (shengqi liuxing 生氣流行). Having reviewed some crucial ideas in the history of philosophy, Chen announces the great ambition to rebuild metaphysics not only for Confucian philosophy but for the foundation and many theories of contemporary philosophy within the framework of humanity; hence he emphasizes the importance of the notion of humanity.

The following two chapters shed light on the ethical meaning of humanity by tracing the origin of the idea in early China and its evolution to prepare for the further discussion of its crucial development in the Song 宋 and the Ming 明 time. The fourth chapter copes with the entity of humanity, which, according to CHENG Hao, is integrated with all things by means of $q i$ 氣, the fundamental medium to link up all things together. Later, ZHU Xi developed a cosmological approach to considering $q i$ 氣 as the substance or entity of humanity, and regarded ceaseless creativity (shengsheng 生生) and love ( $a i$ 愛) as the natural and automatic outcome of $q i$ 氣. Therefore, the entity of humanity is involved in a cosmological and spiritual approach. Chen skillfully bridges the gap between ren 仁 and sheng 生 by reductio ad absurdum. Of special philosophical interest is Chen's argument that there is a problem of entity in Chinese philosophy tradition in the fifth chapter, which is not derived from the discussion of the copula "being." Chen confirms that the theory of entity in Chinese philosophy is relevant to that in the Western, but the former rarely concerns the nature and the pattern of entity rather than the occurrence, utilization, growth, and circulating (fayong liuxing 發用流行) of the entity. Chen convincingly demonstrates that daoti 道體 is the highest entity, and the connotation of daoti would be most analogous to that of "being" in the context of the West.

The sixth chapter provides an in-depth analysis of the mind of the Heaven (tianxin 天心), which refers to the internally predominant orientation of the operations of heaven and earth, cosmos and the world. It is an abstrusely dominant tendency, similar to the mechanism of the human mind's commanding the body. The discussion of the mind of Heaven links directly to ethics and the theory of cultivation (gongfulun 工夫論). ZHU Xi defined the mind of Heaven and Earth (tiandi zhi xin 天地之心) as humanity, resorting to the theory of the Zhouyi 周易. The vigor of the Heaven and Earth lies in human beings, and the vigor of a human being rests on one's mind, so the way that the mind of Heaven and Earth functions is to influence human beings' minds. In the next chapter, Chen discusses the idea of oneness of all things (wanwu yiti 萬物一體) in detail, and comes to the conclusion that the Neo-Confucians of the Song dynasty mainly revealed the subjective goal of the idea of oneness of all things, but WANG Yangming's 王陽明 understanding of the mind of Heaven and Earth indicates a real possibility to go from the spiritually normative state to the original state, that is, from the entity of humanity to the entity of the cosmos. To explain this point further, we need to turn to the eighth chapter, which explores the mind of creativity (shengwu zhi xin 生物之心), primarily based on ZHU Xi's writings that elaborate the structure of the mind of Heaven as 
well as the mind of human beings. The utilization of humanity, which was expressed as both the creativity for Heaven and love for human beings, not only manifests the cosmic significance of humanity, but also expounds the relationship between creativity (sheng 生) and humanity (ren 仁) as well as humanity (ren 仁) and love (ai 愛). Accordingly, the connections and differentiations between the mind of Heaven and the mind of human beings, and between cosmology and ethics, have been established. Carrying the cosmic and ethical connotations, humanity is no longer too far from everyday life; moreover, we can trace back to humanity by means of love (yi ai tui ren 以愛推仁).

In the ninth chapter, Chen explicates the idea of growth and circulation of the vigorous qi (shengqi liuxing 生氣流行), resorting to ZHU Xi's explanations to the Zhouyi 周易. For $\mathrm{ZHU} \mathrm{Xi}$, on the one hand, the four virtues (side 四德) namely yuan 元, heng 亨, $l i$ 利, zhen 貞—are more than patterns (li 理), for the four virtues appropriately embody the course of growth and circulation of vigorous $q i$. They fall into the category of cosmology. On the other, humanity (ren 仁), justice ( $y i$ 義), propriety ( $l i$ 禮), and wisdom ( $z h i$ 智) form the other four virtues, which are categorized into ethics. Gradually, how the four virtues of cosmology are relevant to the four virtues of ethics becomes an increasingly important thesis for Neo-Confucianism. CHENG Hao first offered an analogy between yuan 元 and ren 仁, which inspired ZHU Xi to thoughtfully propose that the four ethical virtues are not only patterns or principles of human beings, but also different phases of the growth and circulation of vigorous qi. In turn, in light of the four cosmological virtues, the understanding to ren, yi, li, and zhi are not patterns or principles of nature, but different forms of the growth and circulation of vigorous $q i$.

The next two chapters discuss modern philosophers' views of humanity. The tenth chapter analyzes the theories of humanity by XIONG Shili 熊十力, MA Yifu 馬一浮, and LIANG Shuming 梁漱溟, respectively. Chen claims that Xiong's idea in his old age is particularly notable, for Xiong pointed out a possibility to build philosophy which goes beyond the Cheng-Zhu 程朱 School and the Lu-Wang 陸王 School. The eleventh chapter is a response to Li Zehou's 李澤厚 philosophy of emotional entity. When Li sketches his theory of emotional entity in his new books, he urges Chinese philosophers to establish their own philosophy by exploring China's own resources. After comparing his ontology of humanity with Li's ontology of emotion, Chen finds some similarities. Nevertheless, the flaws of Li's metaphysics are evident. For example, it is hard to distinguish the theory of emotional entity from naturalism; also, Li's interpretation of emotion is not philosophical, but anthropological, historical, or psychological.

The last chapter copes with primary modern values pertinent to humanity, and attempts to introduce a vision for the ethics of humanity. First, based on a review of how Confucians constructed the relationship among humanity and other virtues, Chen sequentially advances the theory of four virtues to a new stage by integrating freedom, equality, justice and fairness, and harmony with humanity, which implies that humanity includes and guides the four other virtues (freedom, equality, justice and fairness, and harmony), so the theory of value has to be a monistic system in view of the importance of humanity as the most fundamental and universal value. In particular, humanity demands equality substantially. Modern China's political history has made it clear that the idea of equality in traditional philosophy that is based on humanity is apt to turn 
into social and political equality. Humanity itself means free growing and flowing, so it is lively, active, and vivid. Modern Confucians such as KANG Youwei 康有為, TAN Sitong 譚嗣同, and LIANG Qichao 梁啟超 were convinced that humanity contains equality and freedom, and surely leads to the great harmony (datong 大同). Unlike these philosophers, Chen argues that individual freedom is not isolated from other people, but embodies in the mutual support with others.

In addition, the success and transformation of other virtues such as sincerity, filial piety, and so on, should be predicated on the understanding of humanity; that is to say, a man or a woman is not an isolated person but a member in a social network, so one's interpersonal relationship is not individual-based or rights-based but responsibilitybased. As we know, to be humane (ren 仁) is to stand oneself in the other's shoe, and to give priority to others, so humanity is not self-centered. That is why the awareness of responsibility becomes an intrinsic requirement. Anyone who contrasts Confucian values with contemporary Western ones will find many differences. Chen believes that Confucianism is about the principle of humanity, the spirit of rites, a sense of duty, and a community standard, all of which are quite contrary to individualism. Thus the ontology of humanity provides people a new perspective to reflect on individualism and liberalism.

If we regarded Chen as a brilliant historian of philosophy, now he makes a successful transformation to an original philosopher. Chen provides the most systematic philosophy in mainland China in recent years. His effort clarifies the history of humanity, and introduces a striking, provocative, and complicated argumentation to accomplish an ontology, even metaphysics, of humanity. Because of the depth and breadth of this ontology, it will take scholars some time to examine and assess.

Undoubtedly, Chen tries to prove that humanity is the most fundamental and

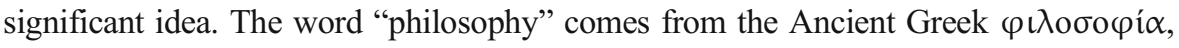
which literally means "love of wisdom." Emmanuel Levinas put it in another way: "philosophy is wisdom of love." Actually, a Confucian is supposed to experience, pursue, and accomplish the values of life which are profoundly rooted in ren'ai 仁愛 (humanity and love). So the ontology of humanity, which is close to "wisdom of love" according to Chen, allows the possibility to improve and modify the self-understanding and introspection of philosophy. If this is the case, then the greatest inspiration Chen's book offers is that we need to reconsider the discourse of philosophy in order to reorient in a different way to understand self, family, society, state, world, nature, and others.

Open Access This article is distributed under the terms of the Creative Commons Attribution 4.0 International License (http://creativecommons.org/licenses/by/4.0/), which permits unrestricted use, distribution, and reproduction in any medium, provided you give appropriate credit to the original author(s) and the source, provide a link to the Creative Commons license, and indicate if changes were made. 